\title{
Study of Structural and Dielectrical Properties of Lead Free Polycrystalline Electro Ceramics $\mathrm{Ba}_{5} \mathrm{CaTi}_{2} \mathrm{Nb}_{8} \mathrm{O}_{30}$ (BCTN) for Microwave Tunable Device Applications
}

\author{
Shilpi Jindal1, Sheela Devi², Ajay Vasishth³, Gagan Kumar1 \\ ${ }^{1}$ Department of Physics, Chandigarh University, Mohali, Punjab, India \\ ${ }^{2}$ Department of Applied Sciences, MSIT, New Delhi, India \\ ${ }^{3}$ Department of Applied Sciences, Chandigarh Engineering College, Punjab, India \\ Email: shilpi.85bansal@gmail.com
}

How to cite this paper: Jindal, S., Devi, S., Vasishth, A. and Kumar, G. (2018) Study of Structural and Dielectrical Properties of Lead Free Polycrystalline Electro Ceramics $\mathrm{Ba}_{5} \mathrm{CaTi}_{2} \mathrm{Nb}_{8} \mathrm{O}_{30}$ (BCTN) for Microwave Tunable Device Applications. Materials Sciences and Applications, 9, 55-67.

https://doi.org/10.4236/msa.2018.91004

Received: October 18, 2017

Accepted: January 5, 2018

Published: January 8, 2018

Copyright $\odot 2018$ by authors and Scientific Research Publishing Inc. This work is licensed under the Creative Commons Attribution International License (CC BY 4.0).

http://creativecommons.org/licenses/by/4.0/

\begin{abstract}
Tungsten bronze structure ceramics have found vital potential in many applications such as actuators, transducer, electro-optic, ferroelectric random access memory and microwave devices. These type ceramics are extensively used in many industrial applications due to their spontaneous polarization and wellknown for its high dielectric constant, low dielectric loss, low leakage current density, good thermal stability and high piezoelectric coefficient. In present work, $\mathrm{Ba}_{5} \mathrm{CaTi}_{2} \mathrm{Nb}_{8} \mathrm{O}_{30}$ (BCTN) has been synthesized first time through solid state reaction method. The microstructures, dielectric, ferroelectric, ferromagnetic and Raman spectra have been investigated by means of X-ray diffraction, Scanning electron microscopy (SEM), energy dispersive X-ray analysis (EDAX), LCR meter, P-E loop tracer, VSM and Raman spectrometer respectively. $\mathrm{X}$-ray diffraction study revealed the formation of single phase tetragonal structure with space group P4bm. The crystallite size was observed to be in the range $14.4 \mathrm{~nm}$. Detailed dielectric properties of BCTN compound as function of temperature at different frequencies show that sample exhibits diffuse type transition at curie temperature $316^{\circ} \mathrm{C}$. The P-E and $\mathrm{M}-\mathrm{H}$ studies confirmed the coexistent ferroelectricity and magnetism at room temperature.
\end{abstract}

\section{Keywords}

Ceramic, X-Ray Diffraction, Scanning Electron Microscopy, Raman Spectrometer 


\section{Introduction}

Tungsten bronze (TB) ferroelectric materials belong to the most important family of dielectric material. Due to their flexible and open nature structure, this compound received extraordinary attention and has been found to be beneficial for various device applications such as transducers, actuators, electro-optic device, piezoelectric sensors, and FERM (ferroelectric random access memories) etc. [1] [2] [3] [4] [5]. Tungsten bronze (TB) structure compound consisting of a framework of distorted $\mathrm{BO}_{6}$ octahedral corner sharing by three different types of interstices $(\mathrm{A}, \mathrm{B}, \mathrm{C})$ which are available for many cations occupation having general formula $\left(A_{1}\right)_{2}\left(A_{2}\right)_{4}(C)_{4}\left(B_{1}\right)_{2}\left(B_{2}\right)_{8} O_{3}[6]$ where $A_{1}$ and $A_{2}$ sites are commonly filled by divalent or trivalent cations, $B_{1}$ and $B_{2}$ sites by tetravalent or pentavalent cations and $\mathrm{C}$ site being small, regularly remains vacant giving the general formula $\mathrm{A}_{6} \mathrm{~B}_{10} \mathrm{O}_{30}$. So in comparison to provskite structure, there is a scope for substitution of several cations at different interstitial sites (i.e., $A_{1}, A_{2}$, $B_{1}$ and $B_{2}$ ) that may alter the physical properties of the compound for various device applications [7]. Ganguly et al. [8] have been reported the structural, dielectric and electrical studies of $\mathrm{Ba}_{5} \mathrm{SmTi}_{3} \mathrm{Nb}_{7} \mathrm{O}_{30}$ ferroelectric ceramics. Wang Chen et al. [9] have been reported the structural, dielectric and magnetic properties of $\mathrm{Ba}_{3} \mathrm{SrLn}_{2} \mathrm{Fe}_{2} \mathrm{Nb}_{8} \mathrm{O}_{30}(\mathrm{Ln}=\mathrm{La}, \mathrm{Nd}, \mathrm{Sm})$ filled tungsten bronze ceramics. From extensive literature study, it has been analyzed that lots of works have been done on rare earth substituted compound of these families such as $\mathrm{Ba}_{5} \mathrm{RTi}_{3} \mathrm{Nb}_{7} \mathrm{O}_{30}$, $\mathrm{Ba}_{4} \mathrm{R}_{2} \mathrm{Ti}_{4} \mathrm{Nb}_{6} \mathrm{O}_{30}(\mathrm{R}=\mathrm{Nd}, \mathrm{Sm}, \mathrm{Eu}, \mathrm{Gd}, \mathrm{Dy}), \mathrm{Ba}_{5} \mathrm{HoTi}_{3} \mathrm{~V}_{7} \mathrm{O}_{30}$ which shows diffused phase transition above room temperature [10] [11] [12] [13] [14] and $\mathrm{Ba}_{6} \mathrm{MNb}_{9} \mathrm{O}_{30}$ $(\mathrm{M}=\mathrm{Ga}, \mathrm{Sc}, \mathrm{In}), \mathrm{Sr}_{4} \mathrm{CaLaTi}_{3} \mathrm{Nb}_{7} \mathrm{O}_{30}$ showing relax or behaviour with tetragonal tungsten bronze structure [15]. It is well known fact that the properties of BCTN are dependent on the particle size, type of substituent and the synthesizing technique. Since there is no report available on the synthesizing of BCTN tungsten bronze ceramic by solid state reaction method, therefore, we aimed to synthesize $\mathrm{Ba}_{5} \mathrm{CaTi}_{2} \mathrm{Nb}_{8} \mathrm{O}_{30}$ (BCTN) polycrystalline compound by solid state reaction technique and motivated to investigate the effect of synthesizing technique on the phase, microstructure, ferroelectric, ferromagnetic and Raman properties of BCTN ceramic.

\section{Experimental}

Polycrystalline sample of composition $\mathrm{Ba}_{5} \mathrm{CaTi}_{2} \mathrm{Nb}_{8} \mathrm{O}_{30}$ (BCTN) was synthesized by solid state reaction method. Reagents grade $\mathrm{BaCO}_{3}$ (99.9\%), $\mathrm{CaCO}_{3}$ (99.9\%), $\mathrm{TiO}_{2}$ (99\%) and $\mathrm{Nb}_{2} \mathrm{O}_{5}$ (99.9\%) (All from M/S Aldrich, USA) used as starting precursor. All starting precursor material was taken into their stoichiometric proportions. The material was thoroughly grind in an agate mortar for $7-8$ hours and then passed through sieve of appropriate size ( 75 micron). The grind powder mixture was calcined at $1100^{\circ} \mathrm{C}$ for $20 \mathrm{hrs}$ in an alumina crucible to form desired phase. Then calcined yellowish color obtained solid solution ground and subsequently admixed with $5 \mathrm{wt} \%$ polyvinyl alcohol (M/S Aldrich, 
USA) as binder and then compacted into pellets of approximately $10 \mathrm{~mm}$ diameter and $1 \mathrm{~mm}$ thickness at a pressure of $100 \mathrm{kN}$. The compact pellets sintered at $1300^{\circ} \mathrm{C}$ for $10 \mathrm{hrs}$. The phase and crystallographic structure of prepared samples were examined by X-ray diffractometer (Bruker D8Advance) in the range $10^{\circ}<2 \theta<70^{\circ}$ with $\mathrm{CuK} \alpha$ radiation having the wavelength of $1.540 \AA$ with scanning rate $1 \%$ minute. The microstructural features and surface morphology of sintered pellets were analyzed using scanning electron microscope (Hitachi S-3700 N). The sintered pellets were polished to $10 \mathrm{~mm}$ thickness and applied silver paste on both sides of pellets to form electrodes, the pellets were then cured at $350^{\circ} \mathrm{C}$ for 30 minutes. The dielectric measurement was carried out using LCR meter (Agilent 4284A) operating at oscillation amplitude 1 V. P-E hysteresis loops were recorded at room temperature using an automatic hysteresis loop tracer based on Sawyer-Tower circuit. The magnetic properties were determined by using Lake-Shore's fully integrated sample magnetometer Raman measurement was performed using Horiba Jobin-Yvon LabRAM HR model equipped with a laser of $514.5 \mathrm{~nm}$ wavelengths in the scan range of $100-1600$ $\mathrm{cm}^{-1}$.

\section{Result and Discussion}

\subsection{Structural Study}

The observed X-ray diffraction pattern for the synthesized BCTN ceramic is shown in Figure 1. The peak position and relative intensity of all diffraction peak are observed to be matching well with the standard powder diffraction file of JCPDS card No. 00-039-0258 and thereby confirming the tetragonal tungsten bronze structure with space group P4bm. Ganguly, P. et al. [16] have reported

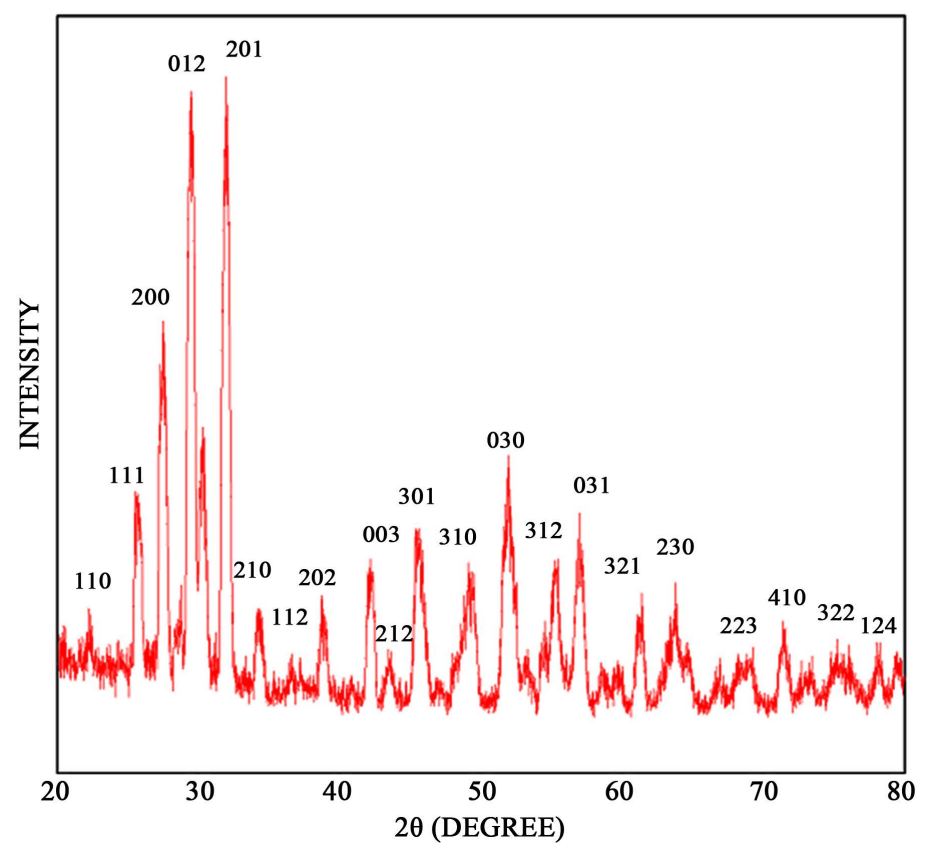

Figure 1. X-ray diffraction patterns of $\mathrm{Ba}_{5} \mathrm{CaTi}_{2} \mathrm{Nb}_{8} \mathrm{O}_{30}$ ceramic. 
the similar diffraction pattern for $\mathrm{Ba}_{5-\mathrm{x}} \mathrm{Ca}_{\mathrm{x}} \mathrm{SmTi}_{3} \mathrm{Nb}_{7} \mathrm{O}_{30}(\mathrm{x}=0)$ synthesized by solid state reaction method. The crystallite size of synthesized BCTN ceramic was calculated by using the Debye Scherer's equation [17] [18]:

$$
D=0.9 \lambda / \beta \cos \theta
$$

where $D$ gives the crystallite size, $\lambda$ is incident wavelength, $\beta$ is FWHM, and $\theta$ is the glancing angle. The observed crystallite size of BCTN was found to be 14.43 $\mathrm{nm}$. The lattice parameters were calculated by using the relation reported by Ganguly et al. [8]. The values of lattice parameters a, b, \& c were observed to be $8.3311 \AA$, $8.3311 \AA$ and $12.1289 \AA$ A respectively.

\subsection{Surface Morphology}

Room temperature SEM micrographs of gold coated BCTN ceramics sintered at $1300^{\circ} \mathrm{C}$ shown in Figure 2. It is observed that specimen has fine grains and
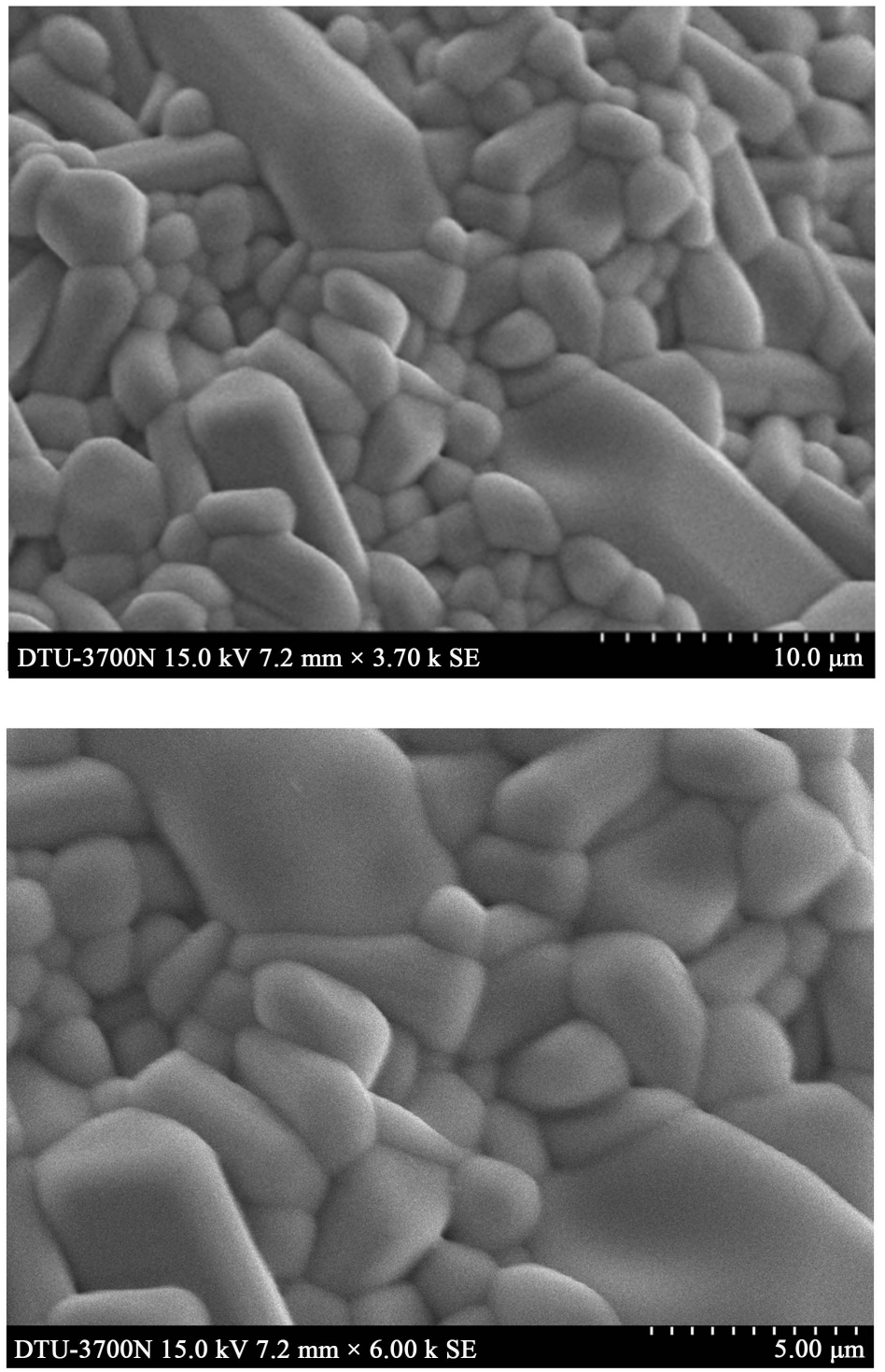

Figure 2. Scanning electron micrographs of $\mathrm{Ba}_{5} \mathrm{CaTi}_{2} \mathrm{Nb}_{8} \mathrm{O}_{30}$ ceramics. 
dense microstructure due to high temperature sintering optimized condition. It is well known that with high sintering temperature well developed grain with uniform grain distribution is observed [19]. The grain size of BCTN ceramic is 6 $\mu \mathrm{m}$. The grain size of BCTN ceramic can be explained on the basis of driving force. This driving force is relative to difference between free energy of strained matrix and strain free crystal. Its result decrease grain boundary area and total boundary energy and increase the grain size of sample. With increasing grain size porosity of specimen decreases [20] [21]. Thus increase in grain and decrease in porosity may be attributed due to small interfacial energy. This interfacial energy is proportional to grain diameter.

\subsection{The Stability of the Crystal Structure}

The stability of the tetragonal tungsten bronze (TTB) structure compound can be determined by Tolerance factor $(t)$ discussed by Wakiya et al. [22] According to the general formula of TTB, two types of A sites are present, one is A1 site with 12 fold coordination which is identical as perovskite structure and A2 site with 15 fold coordination which occupies pentagonal site. Thus value of tolerance factor $(t)$ can be calculated by following relation [23]

$$
\begin{gathered}
t_{A 1}=\left(R_{A 1}+R_{O}\right) /\left(\sqrt{2}\left(R_{B}+R_{O}\right)\right) \\
t_{A 2}=\left(R_{A 2}+R_{O}\right) / \sqrt{\left(23-12 \sqrt{3}\left(R_{B}+R_{O}\right)\right)}
\end{gathered}
$$

where $t_{A 1}$ and $t_{A 2}$ represent the tolerance factor of $\mathrm{A}_{1}$ and $\mathrm{A}_{2}$ sites, $R_{A}, R_{B}$ and $R_{O}$ are ionic radius of $A$ sites, $B$ sites and oxygen respectively.

In TTB structure tolerance factor and stability relationship analyzed by the combined relationship of above two equations which can be expressed as:

$$
t=\left(t_{A 1}+2 t_{A 2}\right) / 3
$$

The crystal structure is stable when value of $t$ is closer to 1 . Since the calculated value of tolerance factor $(t)$ for BCTN ceramic is 0.63640 which is slightly small than 1 hence showing a slight instability of the synthesized TB ceramics.

\subsection{EDAX Studies}

In order to confirm the chemical composition and stoichiometric proportions of the typical samples of $\mathrm{Ba}_{5} \mathrm{CaTi}_{2} \mathrm{Nb}_{8} \mathrm{O}_{30}$ (BCTN) ceramics, energy dispersive analysis of X-ray (EDAX) study is carried out and the typical EDAX spectra for ceramic is presented in Figure 3. All the ions present in $\mathrm{Ba}_{5} \mathrm{CaTi}_{2} \mathrm{Nb}_{8} \mathrm{O}_{30}$ ceramics are observed to be in good stoichiometric proportions as desired. Table 1 shows the elemental percentage and calculated atomic formula with nominal composition.

\subsection{Dielectric Studies}

It is well known that the dielectric constant and dielectric loss of the ferroelectric 


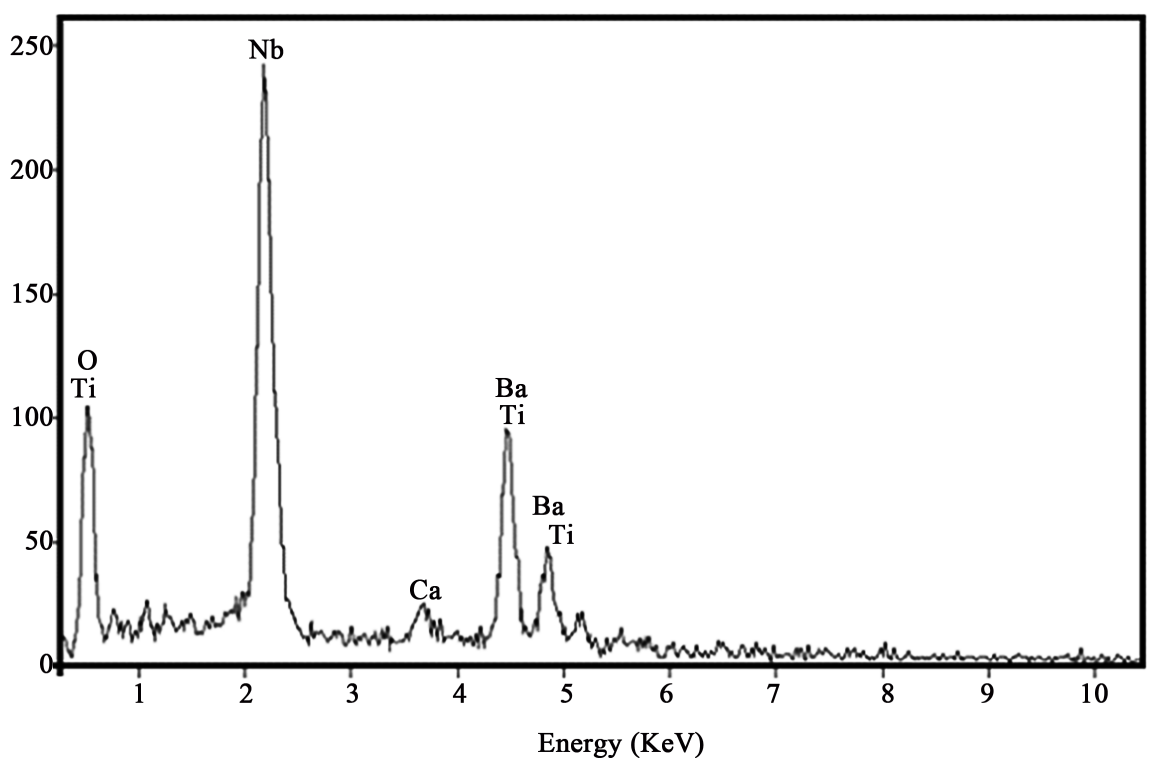

Figure 3. EDAX patterns of $\mathrm{Ba}_{5} \mathrm{CaTi}_{2} \mathrm{Nb}_{8} \mathrm{O}_{30}$ ceramics.

Table 1. $\mathrm{Ba}_{5} \mathrm{CaTi}_{2} \mathrm{Nb}_{8} \mathrm{O}_{30}$ ceramics elemental percentage and calculated atomic formula with nominal composition.

\begin{tabular}{ccccc}
\hline Element line & Net count & Weight\% & Atom\% & Formula \\
\hline O K & 754 & 22.55 & 64.65 & $\mathrm{O}$ \\
$\mathrm{Ca} \mathrm{K}$ & 127 & 1.20 & 1.37 & $\mathrm{Ca}$ \\
$\mathrm{Ca} \mathrm{L}$ & 0 & - & - & \\
$\mathrm{Ti} \mathrm{K}$ & 223 & 2.90 & 2.78 & $\mathrm{Ti}$ \\
$\mathrm{Ti} \mathrm{L}$ & 0 & - & - & \\
$\mathrm{NbK}$ & 0 & - & - & $\mathrm{Nb}$ \\
$\mathrm{NbL}$ & 4005 & 42.04 & 20.75 & \\
$\mathrm{NbM}$ & 0 & - & - & $\mathrm{Ba}$ \\
Ba L & 1586 & 31.31 & 10.46 & \\
Ba M & 0 & - & - & \\
Total & & 100 & 100 & \\
\hline
\end{tabular}

materials depends upon the composition, grain size etc. Figure 4(a) and Figure 4(b) show the temperature dependence of dielectric constant $\left(\varepsilon^{\prime}\right)$ at frequencies of $1 \mathrm{kHz}, 10 \mathrm{kHz}, 100 \mathrm{kHz}$. In $\mathrm{Ba}_{5} \mathrm{CaTi}_{2} \mathrm{Nb}_{8} \mathrm{O}_{30}$ compound, shows the sharp transition in dielectric constant at Curie temperature $T_{\mathcal{C}}$ where dielectric constant is maximum. It is observed that compound has dielectric anomaly at $316^{\circ} \mathrm{C}$ (the Curie temperature $T_{c}$ ) depicts the occurrence of ferroelectric-paraelectric phase transition [24]. It is also analyzed that compound has the same transition temperature $\left(T_{c}\right)$ at above revealed frequencies, indicating that compound does not have relax or behavior. 


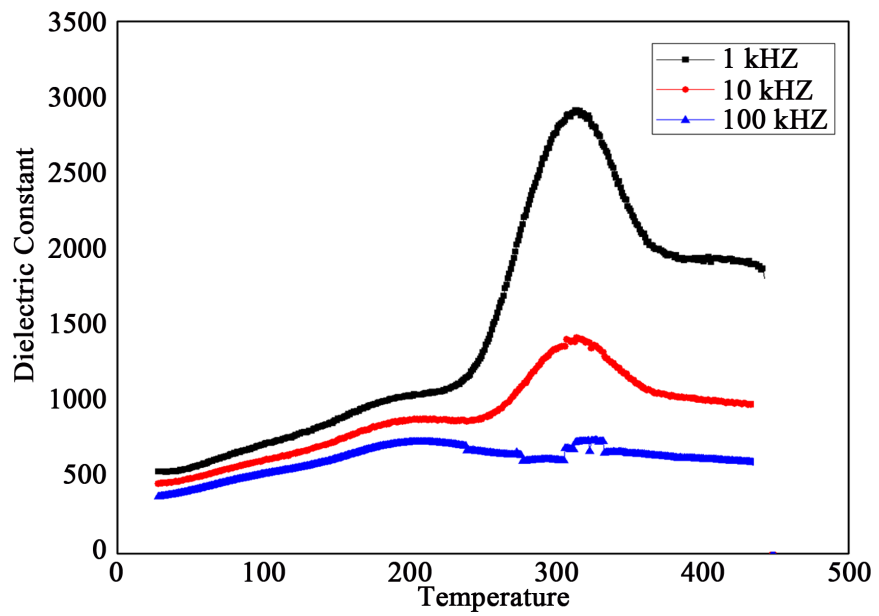

(a)

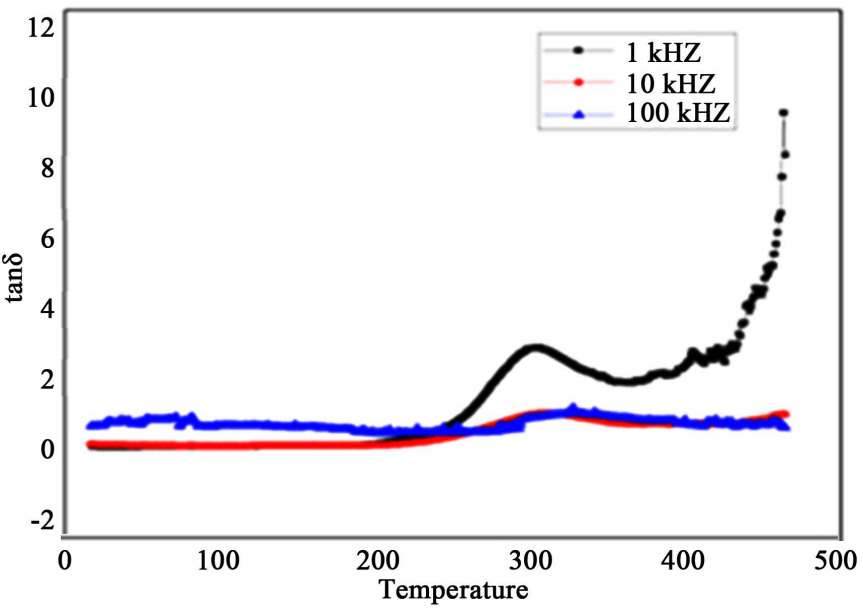

(b)

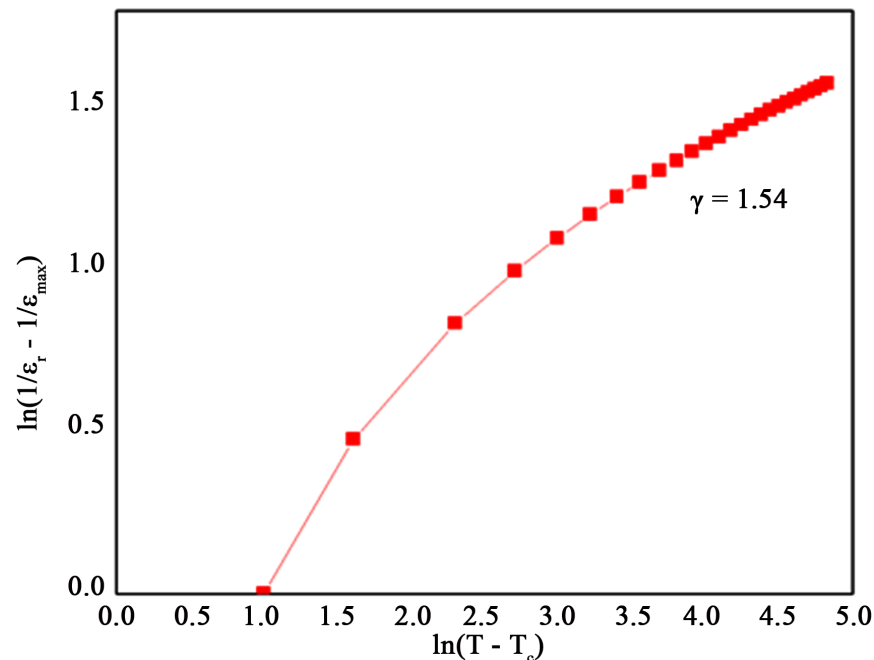

(c)

Figure 4. (a) Variation of dielectric constant with temperature at $1 \mathrm{kHz}, 10 \mathrm{kHz}$ and 100 $\mathrm{kHz}$ of $\mathrm{Ba}_{5} \mathrm{CaTi}_{2} \mathrm{Nb}_{8} \mathrm{O}_{30}$ ceramic; (b) Variation of dielectric loss with temperature at 1 $\mathrm{kHz}, 10 \mathrm{kHz}$ and $100 \mathrm{kHz}$ of $\mathrm{Ba}_{5} \mathrm{CaTi}_{2} \mathrm{Nb}_{8} \mathrm{O}_{30}$ ceramic; (c) Variation of $\ln \left(1 / \varepsilon_{r}-1 / \varepsilon_{\text {max }}\right)$ with $\ln \left(T-T_{c}\right)$ at $100 \mathrm{kHz}$ of $\mathrm{Ba}_{5} \mathrm{CaTi}_{2} \mathrm{Nb}_{8} \mathrm{O}_{30}$ ceramic. 
The increase in value of dielectric constant can be understood as: The sintering of compound is carried out in muffle furnace of very high temperature, so there is possibility of re-oxidation around the grain during the cooling process and lattice pick up oxygen vacancies from the ambient. This re-oxidation creates a strong insulating layer around the grain with bulk resistance. Its result can developed very large conductive difference between bulk and grain boundary. And grain boundary is responsible for large capacitance and resistance compared to grain interior subsequent to surface charge accumulation and interfacial polarization therefore leads to increase dielectric constant [25] [26] [27]. Secondly, the value of maximum dielectric constant can be attributed due to well defined or well developed grain and shown in Figure 2. Well defined grain makes the domain wall motion easier and due to this dielectric constant value increase.

\section{Diffuse phase transition}

The dielectric peak is broadened indicating the existence of diffuse phase transition. The quantitative evaluation of the diffusivity or disorderness in a sample can be calculated by modified Curie-Weiss law [28]:

$$
\ln \left(1 / \varepsilon_{r}-1 / \varepsilon_{\max }\right)=\gamma \ln \left(T-T_{c}\right)+\text { constant }
$$

where, $\varepsilon_{r}$ is relative permittivity at temperature $T$ and $\varepsilon_{\max }$ is maximum relative permittivity at temperature $T_{\mathcal{o}} C$ 'is Curie constant. The parameter $\gamma$ is regarded as a measure of the diffuseness or disorderness of the ferroelectric to paraelectric phase transition. $\gamma=1$ corresponds to the normal ferroelectric behavior while $\gamma$ lies between 1 (normal Curie-Weiss behavior) and 2 (for completely disordered system) confirming the diffuse type phase transition in the sample [29]. In present work value of $\gamma$ observed in between $1<\gamma<2$, that is correspond to diffuse phase transition. This observation is in conformity with observed phase transition in Figure 4(a).

The plots of $\ln \left(1 / \varepsilon_{r}-1 / \varepsilon_{\max }\right)$ as a function of $\ln \left(T-T_{c}\right)$ at $1 \mathrm{kHz}, 10 \mathrm{kHz}$ and $100 \mathrm{kHz}$ are shown in Figure 4(c). The calculated value of diffusivity was found to be $\gamma=1.54$ in the material which show the existence of diffuse phase transition in the material.

Figure 4(b) shows the temperature variation of dielectric loss $(\tan \delta$ ) from room temperature to $500^{\circ} \mathrm{C}$ at the frequencies of $1 \mathrm{kHz}, 10 \mathrm{kHz}$ and $100 \mathrm{kHz}$. This anomaly in $\tan \delta$ (of diffuse type material) may be accepted due to dielectric relaxation in the material. At above mentioned frequencies, the variation of dielectric loss with temperature show that dielectric loss has smaller value at lower temperature but its value increase sharply at higher temperature [30]. This sharp increase in $\tan \delta$ at higher temperature may be attributed due to ferroelectric domain wall contribution and space charge polarization. It is observed that $\mathrm{Ba}_{5} \mathrm{CaTi}_{2} \mathrm{Nb}_{8} \mathrm{O}_{30}$ (BCTN) ceramic has large dielectric constant and low dielectric loss which make it suitable material for tunable device applications.

\subsection{Raman Spectroscopy}

Raman spectroscopy is powerful tool to study the local distortion, strain and any 
disorder present in crystalline solids because vibrational spectrum having shorter length scale characteristic. In Figure 5 Raman spectra plotted intensity versus the difference in wave number between incident beam and scattered beam and peak observed in correspondence to phonon frequency [31]. In present work Raman scattering used to study the change in degree of ordering and any distortion present in the sample [32] [33]. Recently this spectroscopy used for the study of multiferroic materials. Room temperature Raman spectra of BCTN compound studied in frequency range $50-1600 \mathrm{~cm}^{-1}$ which depicts various mode of vibrations i.e. $\mathrm{A}_{1}\left(\mathrm{TO}_{1}\right), \mathrm{A}_{1}\left(\mathrm{TO}_{2}\right), \mathrm{A}_{1}\left(\mathrm{TO}_{3}\right)$ and $\mathrm{A}_{1}\left(\mathrm{LO}_{1}\right)$ at $265.958 \mathrm{~cm}^{-1}$, $628.33 \mathrm{~cm}^{-1}, 1010.94 \mathrm{~cm}^{-1}$ and $1124.84 \mathrm{~cm}^{-1}$. Peak at low wave number $<200$ $\mathrm{cm}^{-1}$ in Raman spectra rise due to external lattice vibration involving motion of cations relative to oxygen octahedron frame work of $\mathrm{NbO}_{6}$. The sharp $\mathrm{A}_{1}\left(\mathrm{TO}_{2}\right)$ band at $628.33 \mathrm{~cm}^{-1}$ which correspond to vibration of A site against NbO6 octahedral ion at $\mathrm{B}$ site. $\mathrm{A}_{1}\left(\mathrm{TO}_{3}\right)$ mode is due to vibration of $\mathrm{Nb}$ and $\mathrm{O}$ ions which are located in plane perpendicular to it. $A_{1}\left(\mathrm{LO}_{3}\right)$ mode is due to phonon propagating along $\mathrm{c}$ axis which is characteristic feature of tetragonal tungsten bronze structure in BCTN compound. The modes at $265.958 \mathrm{~cm}^{-1}, 628.33 \mathrm{~cm}^{-1}$ and $1010.94 \mathrm{~cm}^{-1}$ signifies long range ferroelectric ordering [34].

\subsection{Ferroelectric and Ferromagnetic Study}

Figure 6 shows the P-E hysteresis loop of sintered sample recorded at room temperature. The observed value of remenant polarization $\left(P_{r}\right)$ is $0.742 \mu \mathrm{C} \cdot \mathrm{cm}^{-2}$ and coercive field $\left(E_{c}\right)$ is $11.805 \mathrm{kV} \cdot \mathrm{cm}^{-1}$.

The variation of magnetization as a function of applied field is shown in Figure 7. The values of magnetic parameters such as saturation magnetization, remanence magnetization, coercivity $\mathrm{H}_{\mathrm{c}}(O e)$, and squareness ratio $\mathrm{M}_{\mathrm{r}} / \mathrm{M}_{\mathrm{s}}$ are observed to be $7.65 \times 10^{-4} \mathrm{emu} / \mathrm{g}, 7.22 \times 10^{-5} \mathrm{emu} / \mathrm{g}, 65.51 \mathrm{Oe}$ and 0.09 respectively.

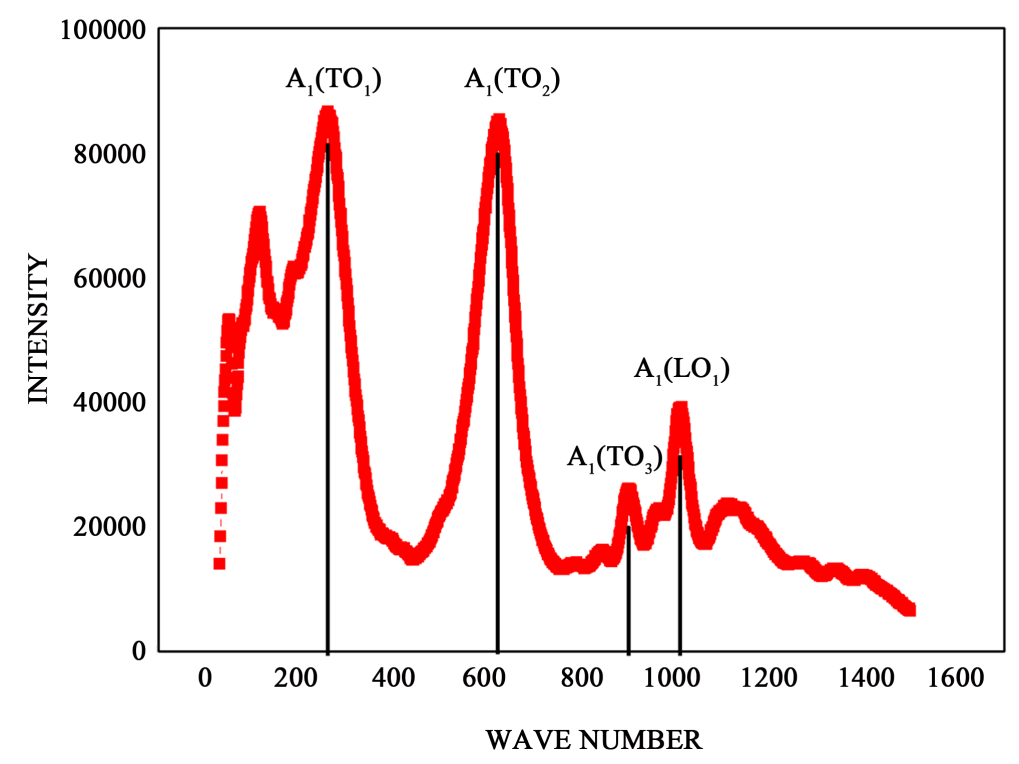

Figure 5. Raman spectra of $\mathrm{Ba}_{5} \mathrm{CaTi}_{2} \mathrm{Nb}_{8} \mathrm{O}_{30}$ (BCTN) compound. 


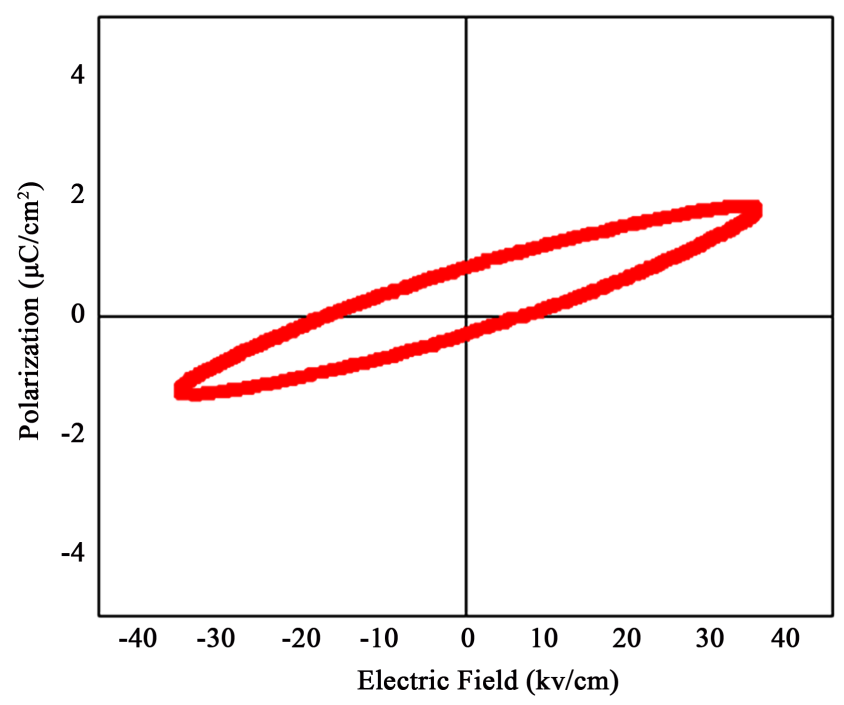

Figure 6. P-E loops of $\mathrm{Ba}_{5} \mathrm{CaTi}_{2} \mathrm{Nb}_{8} \mathrm{O}_{30}$ ceramics.

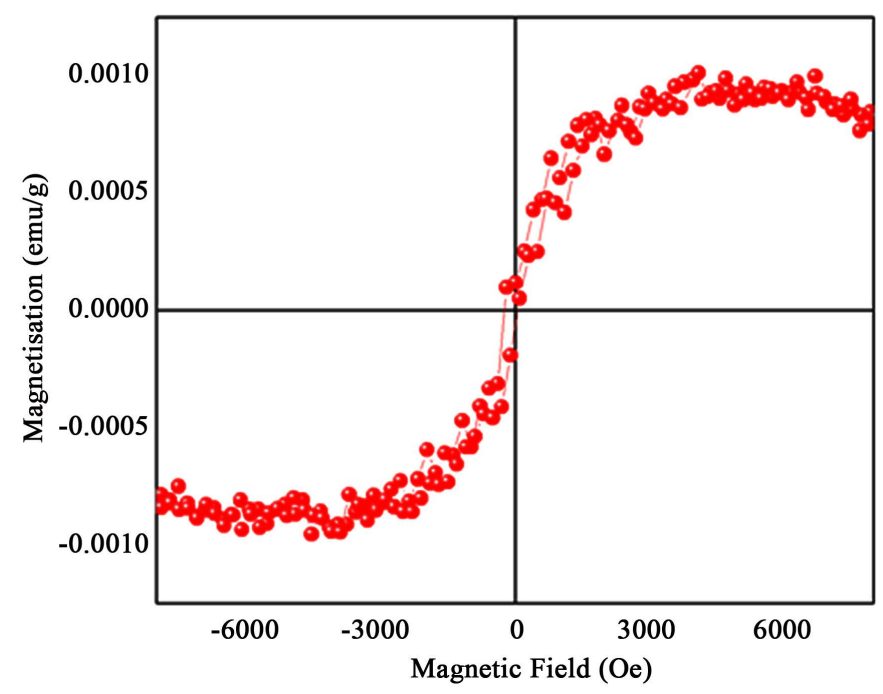

Figure 7. M-H curves of $\mathrm{Ba}_{5} \mathrm{CaTi}_{2} \mathrm{Nb}_{8} \mathrm{O}_{30}$ ceramics.

The ferroelectric ceramic show a strong makeover of diamagnetism to weak ferromagnetism [35] [36]. So the existence of ferromagnetism in BCTN ceramic is as per expectation.

\section{Conclusion}

$\mathrm{Ba}_{5} \mathrm{CaTi}_{2} \mathrm{Nb}_{8} \mathrm{O}_{30}$ ferroelectric ceramic is successfully synthesized by solid state reaction technique with tetragonal phase structure. The SEM micrographs depicted the presence of well-developed grain with uniform grain distribution and the grain size of BCTN ceramic is $6 \mu \mathrm{m}$. BCTN ceramic shows a diffuse phase of ferroelectric-paraelectric phase transition with $T_{c}=316^{\circ} \mathrm{C}$. Dielectric loss is observed to very small loss and it is independent of temperature around $250^{\circ} \mathrm{C}$ then decreases with increasing frequency. Ferroelectric and Ferromagnetism measured at room temperature which predicted a narrow hysteresis loop of 
BCTN ceramics, thereby suggested the utility for microwave tunable device applications.

\section{References}

[1] Kim, J.W. and Heinrich, J.G. (2005) Influence of Processing Parameters on Microstructure and Ferroelectric Properties of PZT-Coated SiC Fibers. Journal of the European Ceramic Society, 25, 1637-1645.

https://doi.org/10.1016/j.jeurceramsoc.2004.05.011

[2] Yang, A., Wang, C.A., Guo, R., Huang, Y. and Nan, C.W. (2010) Effects of Sintering Behavior on Microstructure and Piezoelectric Properties of Porous PZT Ceramics. Ceramics International, 36, 549-554. https://doi.org/10.1016/j.ceramint.2009.09.022

[3] Ortega, R., Loria, A. and Kelly, R. (1995) A Semiglobally Stable Output Feedback PI2D Regulator for Robot Manipulators. IEEE Transactions on Automatic Control, 40, 1432-1436. https://doi.org/10.1109/9.402235

[4] Rhim, S.M., Hong, S., Bak, H. and Kim, O.K. (2000) Effects of $\mathrm{B}_{2} \mathrm{O}_{3}$ Addition on the Dielectric and Ferroelectric Properties of $\mathrm{Ba}_{0.7} \mathrm{Sr}_{0.3} \mathrm{TiO}_{3}$ Ceramics. Journal of the American Ceramic Society, 183, 1145-1148.

[5] Su, B., Holmes, J.E., Cheng, B.L. and Button, T.W. (2002) Processing Effects on the Microstructure and Dielectric Properties of Barium Strontium Titanate (BST) Ceramics. Journal of Electroceramics, 19, 111-116. https://doi.org/10.1023/A:1022850205284

[6] Tan, Y., Zhang, J., Wang, C., Viola, G. and Yan, H. (2015) Enhancement of Electric Field-Induced Strain in $\mathrm{BaTiO}_{3}$ Ceramics through Grain Size Optimization. Physica Status Solidi (a), 212, 433-438.

[7] Ganguly, P., Devi, S., Jha, A.K. and Deori, K.L. (2009) Dielectric and Pyroelectric Studies of Tungsten Bronze Structured $\mathrm{Ba}_{5} \mathrm{SmTi}_{3} \mathrm{Nb}_{7} \mathrm{O}_{30}$ Ferroelectric Ceramics. Ferroelectrics, 381,111-119. https://doi.org/10.1080/00150190902869772

[8] Ganguly, P., Jha, A.K. and Deori, K.L. (2009) Investigations of Dielectric, Pyroelectric and Electrical Properties of $\mathrm{Ba}_{5} \mathrm{SmTi}_{3} \mathrm{Nb}_{7} \mathrm{O}_{30}$ Ferroelectric Ceramic. Journal of Alloys and Compounds, 484, 40-44. https://doi.org/10.1016/j.jallcom.2009.05.034

[9] Chen, W., Yang, W.Z., Liu, X.Q. and Chen, X.M. (2016) Structural, Dielectric and Magnetic Properties of $\mathrm{Ba}_{3} \mathrm{SrLn}_{2} \mathrm{Fe}_{2} \mathrm{Nb}_{8} \mathrm{O}_{30}$ ( $\left.\mathrm{Ln}=\mathrm{La}, \mathrm{Nd}, \mathrm{Sm}\right)$ Filled Tungsten Bronze Ceramics. Journal of Alloys and Compounds, 675, 311-316. https://doi.org/10.1016/j.jallcom.2016.03.099

[10] Shannigrahi, S.R., Choudhary, R.N.P., Kumar, A. and Acharya, H.N. (1998) Phase Transition in $\mathrm{Ba}_{5} \mathrm{RTi}_{3} \mathrm{Nb}_{7} \mathrm{O}_{30}(\mathrm{R}=\mathrm{Dy}, \mathrm{Sm})$ Ferroelectric Ceramics. Journal of Physics and Chemistry of Solids, 59, 737-742. https://doi.org/10.1016/S0022-3697(97)00217-5

[11] Zhu, X.-L. and Chen, X.-M. (2014) Ferroelectric Transition and Curie Weiss Behavior in Some Filled Tungsten Bronze Ceramics. Chinese Physics Letters, 131, 015201.

[12] Fang, L., Zhang, H., Yang, J.F., Meng, F.C. and Yuan, R.Z. (2003) Structural and Dielectric Properties of Ferroelectric $\mathrm{Sr}_{5} \mathrm{RTi}_{3} \mathrm{Nb}_{7} \mathrm{O}_{30}(\mathrm{R}=\mathrm{Nd}$ and $\mathrm{Y})$ Ceramics. Journal of Materials Science Letters, 22, 1705-1707. https://doi.org/10.1023/B:JMSL.0000004654.78051.d3

[13] Zhang, H., Fang, L., Huang, T.H., Liu, H.X., Yuan, R.Z. and Dronskowski, R. (2005) Structural and Dielectric Properties of Ferroelectric $\mathrm{Sr}_{4} \mathrm{R}_{2} \mathrm{Ti}_{4} \mathrm{Nb}_{6} \mathrm{O}_{30}(\mathrm{R}=\mathrm{Sm}$ and $\mathrm{Nd}$ ) Ceramics. Journal of Materials Science, 40, 529-531. https://doi.org/10.1007/s10853-005-6121-3 
[14] Kathayat, K., Panigrahi, A., Pandey, A. and Kar, S. (2012) Characterization of Electrical Behavior of $\mathrm{Ba}_{5} \mathrm{HoTi}_{3} \mathrm{~V}_{7} \mathrm{O}_{30}$ Ceramic Using Impedance Analysis. Materials Sciences and Applications, 3, 390. https://doi.org/10.4236/msa.2012.36056

[15] Zerihun, G., Gong, G., Huang, S. and Yuan, S. (2015) Dielectric and Relaxor Ferroelectric Properties of $\mathrm{Sr}_{4} \mathrm{CaLaTi}_{3} \mathrm{Nb}_{7} \mathrm{O}_{30}$ Tetragonal Tungsten Bronze Ceramics. Ceramics International, 41, 12426-12431. https://doi.org/10.1016/j.ceramint.2015.06.084

[16] Ganguly, P. and Jha, A.K. (2010) Structural and Electrical Properties of $\mathrm{Ba}_{5-\mathrm{x}} \mathrm{Ca}_{\mathrm{x}}$ $\mathrm{SmTi}_{3} \mathrm{Nb}_{7} \mathrm{O}_{30}(\mathrm{x}=0$ - 5) Ferroelectric Ceramics. Journal of Alloys and Compounds, 495, 7-12. https://doi.org/10.1016/j.jallcom.2010.01.118

[17] Shukla, A., Choudhary, R.N.P., Thakur, A.K. and Pradhan, D.K. (2010) Structural, Microstructural and Electrical Studies of La and $\mathrm{Cu}$ Doped $\mathrm{BaTiO}_{3}$ Ceramics. Phy sica B: Condensed Matter, 405, 99-106. https://doi.org/10.1016/j.physb.2009.08.075

[18] Das, P.S., Chakraborty, P.K., Behera, B. and Choudhary, R.N.P. (2007) Electrical Properties of $\mathrm{Li}_{2} \mathrm{BiV}_{5} \mathrm{O}_{15}$ Ceramics. Physica B: Condensed Matter, 395, 98-103. https://doi.org/10.1016/j.physb.2007.02.065

[19] Sharma, S., Shamim, K., Ranjan, A., Rai, R., Kumari, P. and Sinha, S. (2015) Impedance and Modulus Spectroscopy Characterization of Lead Free Barium Titanate Ferroelectric Ceramics. Ceramics International, 41, 7713-7722. https://doi.org/10.1016/j.ceramint.2015.02.102

[20] Yang, Z., Fang, L., Liu, L., Hu, C., Chen, X. and Zhou, H. (2012) Dielectric Properties and High-Temperature Dielectric Relaxation of Tungsten-Bronze Structure Ceramics $\mathrm{Ba}_{2} \mathrm{GdFeNbTa}_{3} \mathrm{O}_{15}$. Journal of Materials Science: Materials in Electronics, 23, 229-233. https://doi.org/10.1007/s10854-011-0391-0

[21] Jindal, S., Vasishth, A. and Devi, S. (2015) Structural and Dielectric Properties of Co Substituted Multi Ferroic Ceramics. Journal of Basic and Applied Engineering Research, 2, 1877-1879.

[22] Wakiya, N., Wang, J.K., Saiki, A., Shinozaki, K. and Mizutani, N. (1999) Synthesis and Dielectric Properties of $\mathrm{Ba}_{1-\mathrm{x}} \mathrm{R}_{2 \mathrm{x} / 3} \mathrm{Nb}_{2} \mathrm{O}_{6}$ (R: Rare Earth) with Tetragonal Tungsten Bronze Structure. Journal of the European Ceramic Society, 19, 1071 1075. https://doi.org/10.1016/S0955-2219(98)00376-8

[23] Zhu, X.L., Liu, X.Q. and Chen, X.M. (2011) Crystal Structure and Dielectric Properties of $\mathrm{Sr}_{5} \mathrm{RTi}_{3} \mathrm{Nb}_{7} \mathrm{O}_{30}(\mathrm{R}=\mathrm{La}, \mathrm{Nd}, \mathrm{Sm}$, and $\mathrm{Eu})$ Tungsten Bronze Ceramics. Journal of the American Ceramic Society, 94, 1829-1836.

[24] Hu, C., Hou, L., Fang, L. and Liu, L. (2013) Preparation and Dielectric Properties of Unfilled Tungsten Bronze Ferroelectrics $\mathrm{Ba}_{4} \mathrm{RETiNb}_{9} \mathrm{O}_{30}$. Journal of Alloys and Compounds, 581, 547-552. https://doi.org/10.1016/j.jallcom.2013.07.164

[25] Hu, C., Sun, Z., Zhu, Q., Lu, F., Li, C., Liu, L. and Fang, L. (2016) Relax or Behavior and Ferroelectric Properties of a New $\mathrm{Ba}_{4} \mathrm{SmFe}_{0.5} \mathrm{Nb}_{9.5} \mathrm{O}_{30}$ Tungsten Bronze Ceramic. Ceramics International, 42, 14999-15004. https://doi.org/10.1016/j.ceramint.2016.06.147

[26] Fang, L., Peng, X., Li, C., Hu, C., Wu, B. and Zhou, H. (2010) Dielectric Properties of $\mathrm{Ba}_{4} \mathrm{Sm}_{2} \mathrm{Fe}_{2} \mathrm{M}_{8} \mathrm{O}_{30}(\mathrm{M}=\mathrm{Nb}$, Ta) with Tetragonal Bronze Structure. Journal of the American Ceramic Society, 93, 2430-2433.

[27] Stanculescu, R.E., Ciomaga, C.E., Horchidan, N., Galassi, C., Tufescu, F.M. and Mitoseriu, L. (2016) The Influence of Post-Sintering Re-Oxidation Treatment on Dielectric Response of Dense and Porous $\mathrm{Ba}_{0.70} \mathrm{Sr}_{0.30} \mathrm{TiO}_{3}$ Ceramics. Ceramics International, 42, 527-536. https://doi.org/10.1016/j.ceramint.2015.08.141

[28] Xu, F., Trolier-McKinstry, S., Ren, W., Xu, B., Xie, Z.L. and Hemker, K.J. (2001) Domain Wall Motion and Its Contribution to the Dielectric and Piezoelectric Prop- 
erties of Lead Zirconate Titanate Films. Journal of Applied Physics, 189, 1336-1348. https://doi.org/10.1063/1.1325005

[29] Pilgrim, S.M., Sutherland, A.E. and Winzer, S.R. (1990) Diffuseness as a Useful Parameter for Relaxor Ceramics. Journal of the American Ceramic Society, 73, 31223125.

[30] Egerton, L. and Dillon, D.M. (1959) Piezoelectric and Dielectric Properties of Ceramics in the System Potassium-Sodium Niobate. Journal of the American Ceramic Society, 42, 438-442.

[31] Liu, W.C. (2012) Inelastic Light Scattering Studies of Diffuse Phase Transition in Ferroelectric $\mathrm{Sr}_{1.9} \mathrm{Ca}_{0.1} \mathrm{NaNb}_{5} \mathrm{O}_{15}$ Thin Films. Journal of Raman Spectroscopy, 143, 326-330.

[32] Karan, N.K. (2009) Raman Spectral Studies of $\mathrm{Zr}^{4+}$-Rich $\mathrm{BaZr}_{\mathrm{x}} \mathrm{Ti}_{1-\mathrm{x}} \mathrm{O}_{3}(0.5 \bigotimes \times \times 1.00)$ Phase Diagram. Journal of Raman Spectroscopy, 40, 370-375.

[33] Jindal, S., Vasishth, A., Devi, S. and Singh, B. (2017) Synthesis and Characterization of Polycrystalline $\mathrm{Ba}_{5} \mathrm{CaTi}_{2-\mathrm{x}} \mathrm{M}_{\mathrm{x}} \mathrm{Nb}_{8} \mathrm{O}_{30}(\mathrm{M}=\mathrm{Cu})$ Tungsten Bronze Electro Ceramics. Ferroelectrics, 519, 9-14. https://doi.org/10.1080/00150193.2017.1362278

[34] Zhu, X.L. and Chen, X.M. (2012) Ferroelectric Transition of $\mathrm{Sr}_{5} \mathrm{SmTi}_{3} \mathrm{Nb}_{7} \mathrm{O}_{30}$ Tungsten Bronze Ceramics Investigated Using Differential Scanning Calorimetry and Raman Scattering. Journal of the American Ceramic Society, 95, 3185-3191.

[35] Huo, S.X., Yuan, S.L., Qiu, Y., Ma, Z.Z. and Wang, C.H. (2012) Crystal Structure and Multiferroic Properties of $\mathrm{BiFeO}_{3}-\mathrm{Na}_{0.5} \mathrm{~K}_{0.5} \mathrm{NbO}_{3}$ Solid Solution Ceramics Prepared by Pechini Method. Materials Letters, 68, 8-10. https://doi.org/10.1016/j.matlet.2011.09.081

[36] Dang, N.V., Dung, N.T., Phong, P.T. and Lee, I.J. (2015) Effect of Fe ${ }^{3+}$ Substitution on Structural, Optical and Magnetic Properties of Barium Titanate Ceramics. Physica B: Condensed Matter, 457, 103-107. https://doi.org/10.1016/j.physb.2014.09.046 